\title{
A new euarthropod with 'great appendage'-like frontal head limbs from the Chengjiang Lagerstätte, Southwest China
}

\author{
Robert J. O'Flynn, Denis Audo, Mark Williams, \\ Dayou Zhai, Hong Chen, and Yu Liu
}

\begin{abstract}
Bushizheia yangi gen. et sp. nov. is a euarthropod species from the Cambrian (Series 2, Stage 3) Chengjiang Lagerstätte, Southwest China. Sclerotised dorsal tergites, sclerotisation of post-frontal head limb appendages, and no isolated cephalic sclerite support the euarthropod affinities of $B$. yangi gen. et sp. nov. However, the frontal head limbs resemble in morphology the anteroventral raptorial appendage of radiodonts. Although, due to the absence of critical soft anatomy, we cannot elucidate the exact segmental affinities of these raptorial appendages, the possession of 'great appendage'-like frontal head limbs is important for assessing the range of limb morphology evolved by early euarthropods.
\end{abstract}

Robert J. O'Flynn. Yunnan Key Laboratory for Palaeobiology, Institute of Palaeontology, Yunnan University, 650500 Kunming, China and MEC International Joint Laboratory for Palaeobiology and Palaeoenvironment, Yunnan University, 650500 Kunming, China. liangwangshania@126.com http://orcid.org/0000-0001-9939-6321

Denis Audo. Yunnan Key Laboratory for Palaeobiology, Institute of Palaeontology, Yunnan University, 650500 Kunming, China and MEC International Joint Laboratory for Palaeobiology and Palaeoenvironment, Yunnan University, 650500 Kunming, China. denis.audo@edu.mnhn.fr http://orcid.org/0000-0003-3486-3552

Mark Williams. School of Geography, Geology and the Environment, University of Leicester, University Road, Leicester, LE1 7RH, UK and MEC International Joint Laboratory for Palaeobiology and Palaeoenvironment, Yunnan University, 650500 Kunming, China. mri@leicester.ac.uk Dayou Zhai. Yunnan Key Laboratory for Palaeobiology, Institute of Palaeontology, Yunnan University, 650500 Kunming, China and MEC International Joint Laboratory for Palaeobiology and Palaeoenvironment, Yunnan University, 650500 Kunming, China. dyzhai@ynu.edu.cn Hong Chen. Yunnan Key Laboratory for Palaeobiology, Institute of Palaeontology, Yunnan University,

http://zoobank.org/A1DFE048-F763-4B75-9EF0-A20B9B8CD619

O'Flynn, Robert J., Audo, Denis, Williams, Mark, Zhai, Dayou, Chen, Hong, and Liu, Yu. 2020. A new euarthropod with 'great appendage'-like frontal head limbs from the Chengjiang Lagerstätte, Southwest China. Palaeontologia Electronica, 23(2):a36. https:// doi.org/10.26879/1069

palaeo-electronica.org/content/2020/3115-a-new-cambrian-euarthropod

Copyright: August 2020 Paleontological Society.

This is an open access article distributed under the terms of Attribution-NonCommercial-ShareAlike 4.0 International (CC BY-NC-SA 4.0), which permits users to copy and redistribute the material in any medium or format, provided it is not used for commercial purposes and the original author and source are credited, with indications if any changes are made.

creativecommons.org/licenses/by-nc-sa/4.0/ 
650500 Kunming, China and MEC International Joint Laboratory for Palaeobiology and Palaeoenvironment, Yunnan University, 650500 Kunming, China. chenhong3397258@126.com Yu Liu. Yunnan Key Laboratory for Palaeobiology, Institute of Palaeontology, Yunnan University, 650500 Kunming, China and MEC International Joint Laboratory for Palaeobiology and Palaeoenvironment, Yunnan University, 650500 Kunming, China. yu.liu@ynu.edu.cn http://orcid.org/0000-0002-2346-740X

Keywords: Chengjiang; Euarthropoda; 'great appendage'; new genus; new species; Radiodonta

\section{INTRODUCTION}

Over 250 species have been recorded from the Cambrian Series 2, Stage 3 Chengjiang biota of Yunnan Province, China, with arthropods representing circa $33 \%$ of these species (Hou et al., 2017). These include taxa with soft anatomy preservation that are instrumental to elucidating early euarthropod evolution (e.g., Hou and Bergström, 1997; Stein and Selden, 2011; Chen et al., 2019). Among these, arthropods with a grasping appendage, the so-called great or frontal appendages, are iconic animals of the Chengjiang biota (e.g., Chen et al., 2004; Liu et al., 2007; Fu et al., 2011; Legg and Vannier, 2013; Cong et al., 2014).

Here we describe the euarthropod Bushizheia yangi gen. et sp. nov. from the Chengjiang biota. This species is known only from a single specimen with a well-preserved dorsal exoskeleton that is divided into head, thorax, and pygidium (Figure 1A$B$ ), but is most notable for its long frontal appendages that resemble those of radiodonts and the euarthropod Kiisortoqia soperi Stein, 2010 (see Stein, 2010, figure 7B). We discuss what happened to the 'great appendage' with reference to two possibilities for the evolution of the primary antennae or 'great appendage': (1) that limb-like 'great appendages' evolved to form chelicerae (Chen et al., 2004), i.e., innervated from the deutocerebrum (see Park et al., 2018); or (2) that the labrum represents the transformed frontal 'great appendage' (see Budd, 2002; Eriksson et al., 2003; Scholtz and Edgecombe, 2006), i.e., innervated from the protocerebrum (see Park et al., 2018).

We also provide a detailed description of Bushizheia yangi gen. et sp. nov. and discuss its palaeoecology.

\section{MATERIALS AND METHODS}

A single specimen of Bushizheia yangi gen. et sp. nov. was recovered from the Yu'anshan Member, Chiungchussu Formation at Jiucun Town $\left(24^{\circ} 41^{\prime} 33^{\prime \prime} \mathrm{N}, 102^{\circ} 59^{\prime} 26^{\prime \prime}\right.$ E) (see Du et al., 2018, figure 1), Chengjiang County. The Yu'anshan Member is informally divided stratigraphically into four lithologically and palaeontologically distinctive parts (Zhu et al., 2001). B. yangi gen. et sp. nov. was recovered from the third stratigraphic interval of the Yu'anshan Member from laminated mudstones of the early Cambrian (Series 2, Stage 3). It is deposited in the Yunnan Key Laboratory for Palaeobiology (YKLP 11421) at Yunnan University, Kunming.

The specimen was prepared mechanically with a mounted steel needle under a binocular microscope, where only a small amount of matrix was required to be removed by a gentle scraping action.

Fluorescence microscopy and photography (a Leica DFC7000 T linked to a Leica M205 FA fluorescence stereo microscope) were used to increase the contrast between the specimen (not autofluorescent) and the matrix (weakly autofluorescent). For photographs in natural colour, we captured several images with a Digital SLR Camera (a Canon EOS 5DS R and a Nikon D700) fitted with a $100 \mathrm{~mm}$ and a $105 \mathrm{~mm}$ macro lens, respectively, with extension rings for magnification factors above $1: 1$. The photographs were mostly captured in cross-polarised light to limit reflection of light and increase contrast (Bengtson, 2000). We also captured photographs with cropped light (light coming from a low vertical angle, highlighting structures at the surface) from various angles (default: from the top left) to reveal the micro relief of the fossil. The specimen was also investigated with Computed Tomography using a ZEISS Xradia 520 Versa, but no additional structures were revealed using this method.

Measurements were made on digital photographs using the image processing software ImageJ (Schneider et al., 2012). Morphological characters measured include: (1) the total length, measured from the anterior margin of the head shield to the posterior termination of the tailspine; (2) the head, measured from the anterior margin to 

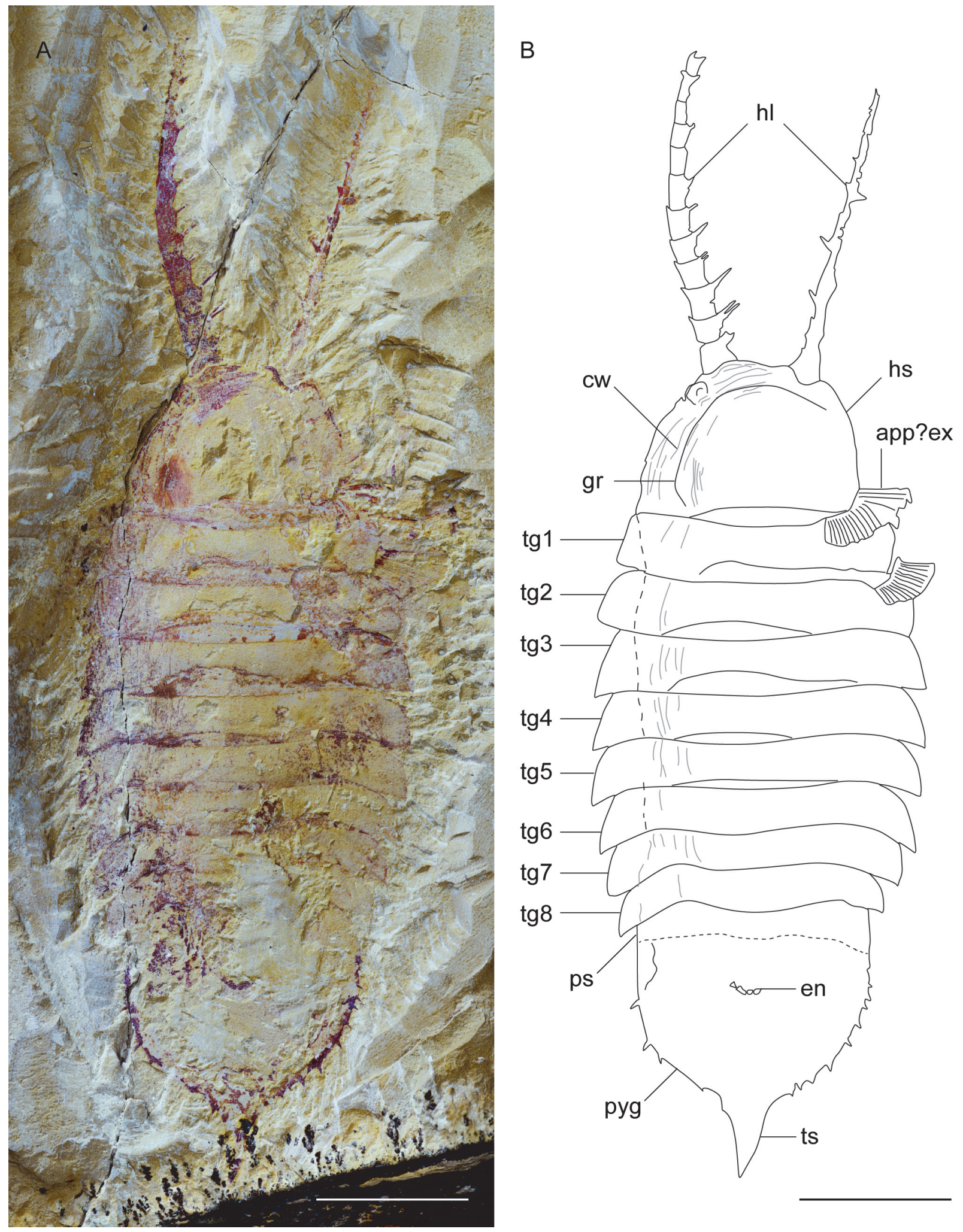

FIGURE 1. Bushizheia yangi gen. et sp. nov. (YKLP 11421). A, photograph of dorsal view; B, composite line drawing of dorsal view. Both scale bars are $10 \mathrm{~mm}$. Abbreviation: app?ex, exopod of a post-frontal head limb appendage; $\mathrm{cw}$, compression wrinkle; en, endopod; gr, groove; hl, frontal head limbs; hs, head shield; ps; pygidial segment; pyg, pygidium; tg1-8, tergites 1 through 8 ; ts, tailspine. 
the posterior margin of the head shield; (3) tergites one through eight, measured from the anterior margin to the posterior margin of the tergite; (4) the frontal head limb, measured from the distal termination to the proximal margin of the podomeres; and (5) the pygidium, measured from the posterior margin of the posterior-most tergite to the posterior termination.

\section{SYSTEMATIC PALAEONTOLOGY}

Phylum EUARTHROPODA Lankester, 1904
Class incertae sedis
Order incertae sedis
Family incertae sedis
Genus Bushizheia O'Flynn and Liu, gen. nov.

zoobank.org/86579E18-E8FD-4D59-840F-8A686585E73F

Type species. Bushizheia yangi gen. et sp. nov., by monotypy.

Diagnosis. As for type species, by monotypy.

Etymology. Bǔshízhě is Mandarin for predator: an allusion to Kiisortoqia Stein, 2010, from the Kalaallisut (Greenlandic) word kiisortoq, meaning predator (see Stein, 2010).

Remarks. Bushizheia gen. nov. is ascribed to the total group Euarthropoda - as defined by the presence of fully arthrodised bodies and limbs (Aria, 2019), because it has sclerotised trunk tergites, sclerotisation of post-antennal appendages (see Cotton and Brady, 2004), and does not have any isolated tergites in the cephalic segments (see Ortega-Hernández, 2014).

It features a long, frontal grasping appendage that is morphologically like that of radiodonts, but in combination with a completely arthrodised body organisation; this distinguishes Bushizheia gen. nov. from all other euarthropods, except Kiisortoqia.

Bushizheia gen. nov. and Kiisortoqia appear allied to each other by the possession of frontal 'great appendage'-like head limbs (Figure 2A-D). However, Bushizheia gen. nov. is sufficiently distinct to warrant erection of a monospecific genus. It differs from Kiisortoqia by: (1) Bushizheia gen. nov. has a large pygidium with paired short falcate spines and a terminal tailspine (Figure 3A); Kiisortoqia has a small tail shield with neither spines nor a tailspine and twice the number of thoracic tergites; see Figure 4B and also Stein, 2010, p. 482483 , figures $4 \mathrm{~B}, 5 \mathrm{~B}-\mathrm{C}$ ); (2) trilobation of thoracic tergites effaced; (3) dorsal spine is present on each podomere of the frontal head limb (see Daley and Edgecombe, 2014).
Bushizheia yangi O'Flynn and Liu, sp. nov. Figures 1A-B, 2A-D, 3A-B, 4A

zoobank.org/6809EBE1-DFB7-4D46-A24C-7F620FFA5FAD

Type material. Holotype YKLP 11421 (Figure 1A) from the Cambrian, Series 2, Stage 3, EoredlichiaWutingaspis trilobite biozone, Nangoan Stage of regional Chinese usage, Yu'anshan Member, Chiungchussu Formation (Repository: YKLP).

Diagnosis. Euarthropod with a semi-circular head shield lacking dorsal compound eyes, eight thoracic tergites, and a large, semi-circular pygidium. Frontal head limbs circa $33 \%$ of body length, strong, composed of $\geq 12$ podomeres, each with paired spines laterally.

Etymology. Yangi, after Mr Zhixin Yang, who recovered and prepared the fossil.

Description. Dorsal aspect of the head shield, trunk, and pygidium (Figures 1A-B, 2C-D, 3A, 4A): Bushizheia yangi gen. et sp. nov. is circa $54 \mathrm{~mm}$ long. The habitus is sub-elliptical in dorsal aspect, with a length (anterior margin of the head shield to the posterior termination of the tailspine) of circa $250 \%$ of the width (maximum width in the anterior half of the body at the third and fourth tergites) (Figures 1A-B, 4A). The length of the head shield is circa $20 \%$ of the total length. The trunk tapers from the fourth tergite backwards to a large pygidium (the tail shield of the exoskeleton covering the fused posterior segments of the body). The pygidium's margin is spinose (Figures 1A-B, 3A, 4A).

The head shield is a simple, semi-circular shield, with smoothly rounded posterolateral margins, and the length is circa $70 \%$ of its width.

The trunk consists of eight tergites. The anterior-most three tergites are virtually of equal length; the length is circa $20 \%$ of the width. Tergites $3-4$ are widest; the width and length of tergites subsequently decrease posteriorly in width and length (Figures 1A-B, 4A). Axially, the posterior border of each tergite overhangs the following tergite by circa $17 \%$ of its length, but by less abaxially. The first, second, and third tergites are reflexed anteriorly, whereas tergites posterior to that are transverse or reflexed posteriorly. The tergopleurae of the first and second tergites terminate bluntly posterolaterally. The tergopleurae of tergites 3-8 are extended into posterolateral projections (Figures 1A-B, 4A).

The pygidium is a semi-circular shield and its length is circa $70 \%$ of its width; the margins bear eight paired short falcate spines, which curve very slightly posteriorly (Figures 1A-B, 3A, 4A). The pleural regions of the pygidium's anterior-most segment are effaced, but a transverse furrow is vis- 

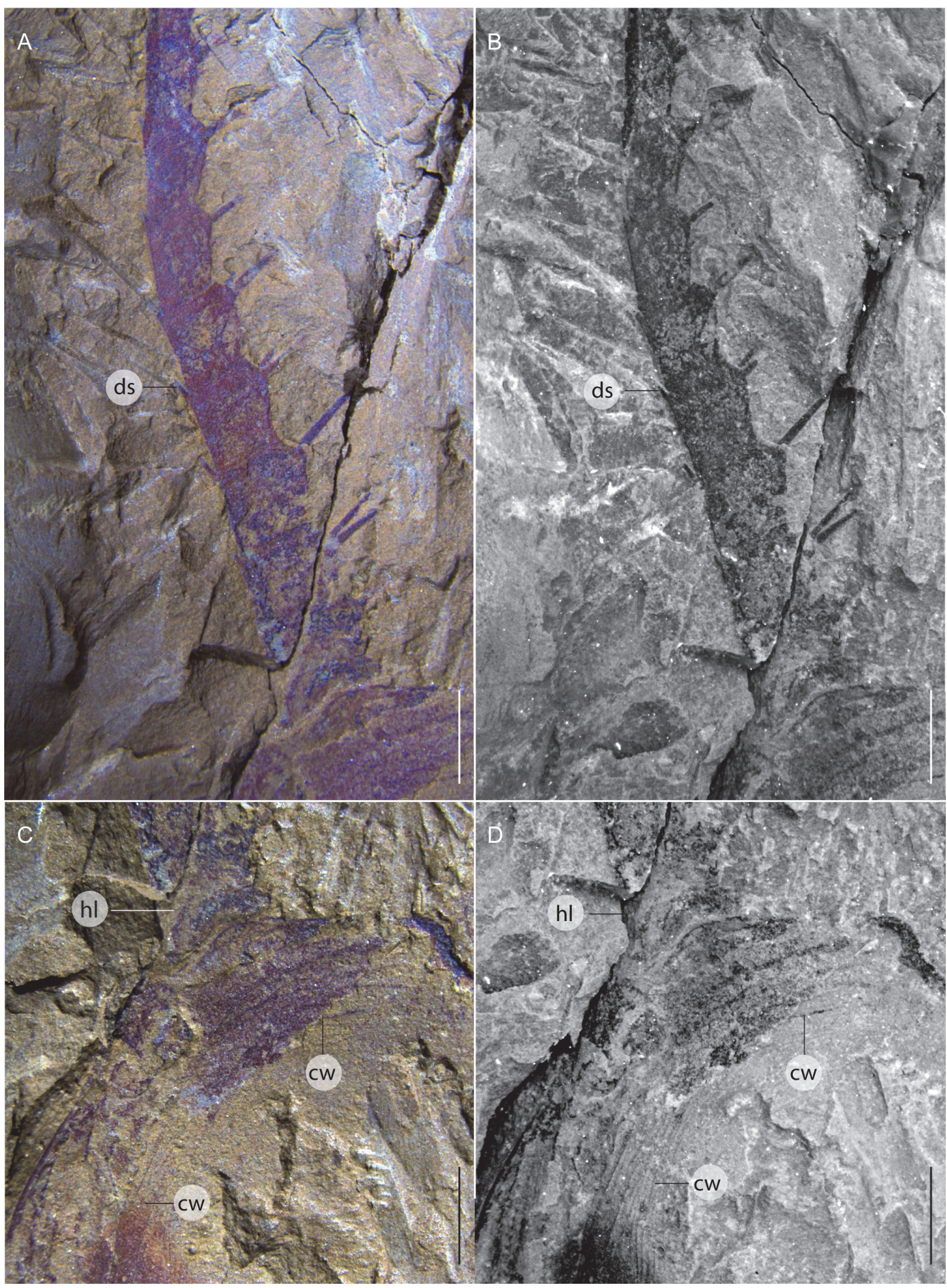

FIGURE 2. Bushizheia yangi gen. et sp. nov. (YKLP 11421). A, C, tungsten photography lighting of left frontal head limb and dorsal view of head shield, respectively; B, D, fluorescent photography lighting of the same. All scale bars are $2 \mathrm{~mm}$. Abbreviation: cw, compression wrinkles; ds, dorsal spines; hl, frontal head limb. 

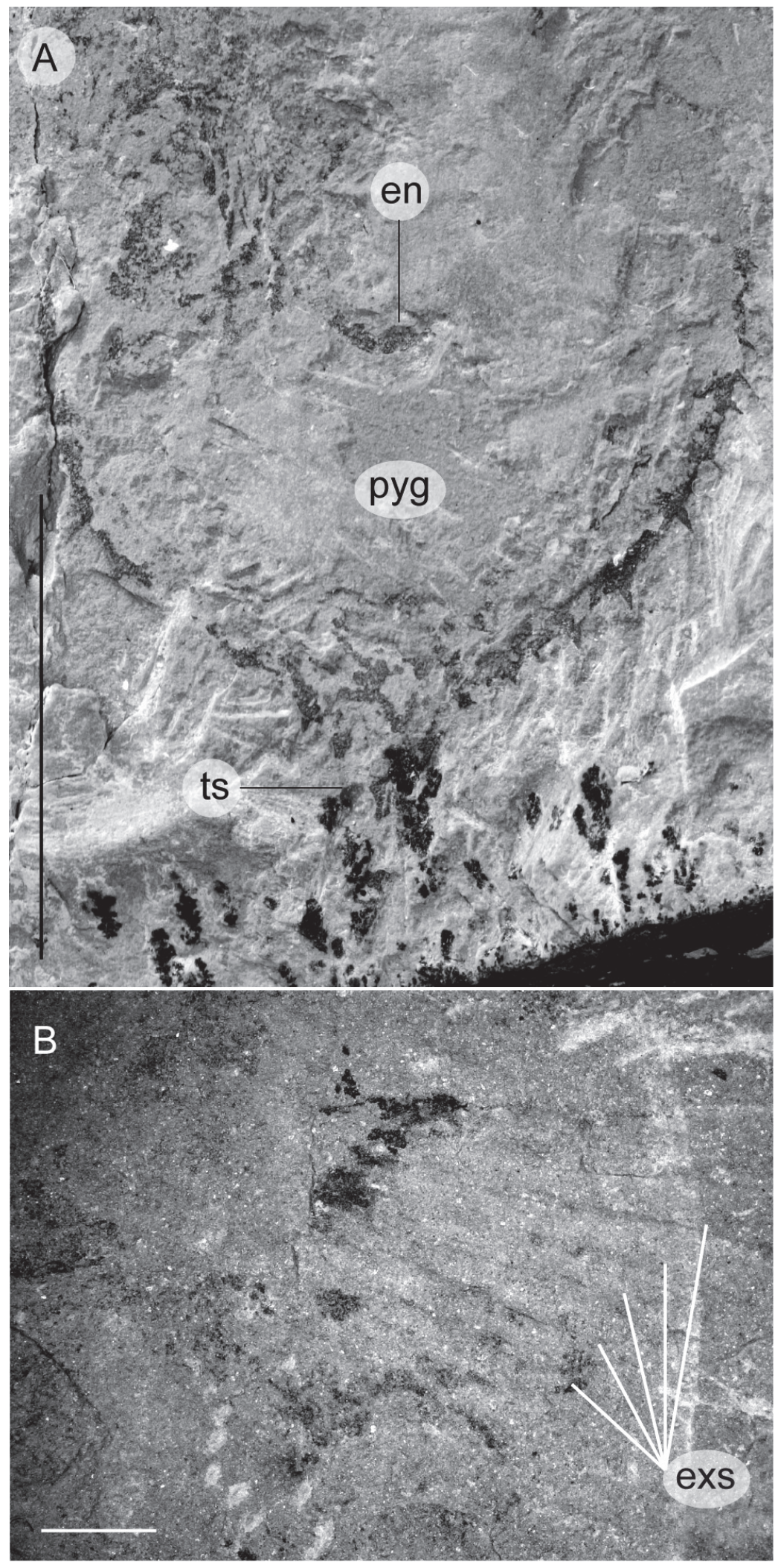

FIGURE 3. Bushizheia yangi gen. et sp. nov. (YKLP 11421). A-B, enlarged from Fig. 1A; A, detail of pygidium; B, detail of exopod setae. Scale bar $3 A$ is $10 \mathrm{~mm}$. Scale bar 3B is $1 \mathrm{~mm}$. Abbreviation: en, endopod; exs, exopod setae; pyg, pygidium; ts, tailspine. 

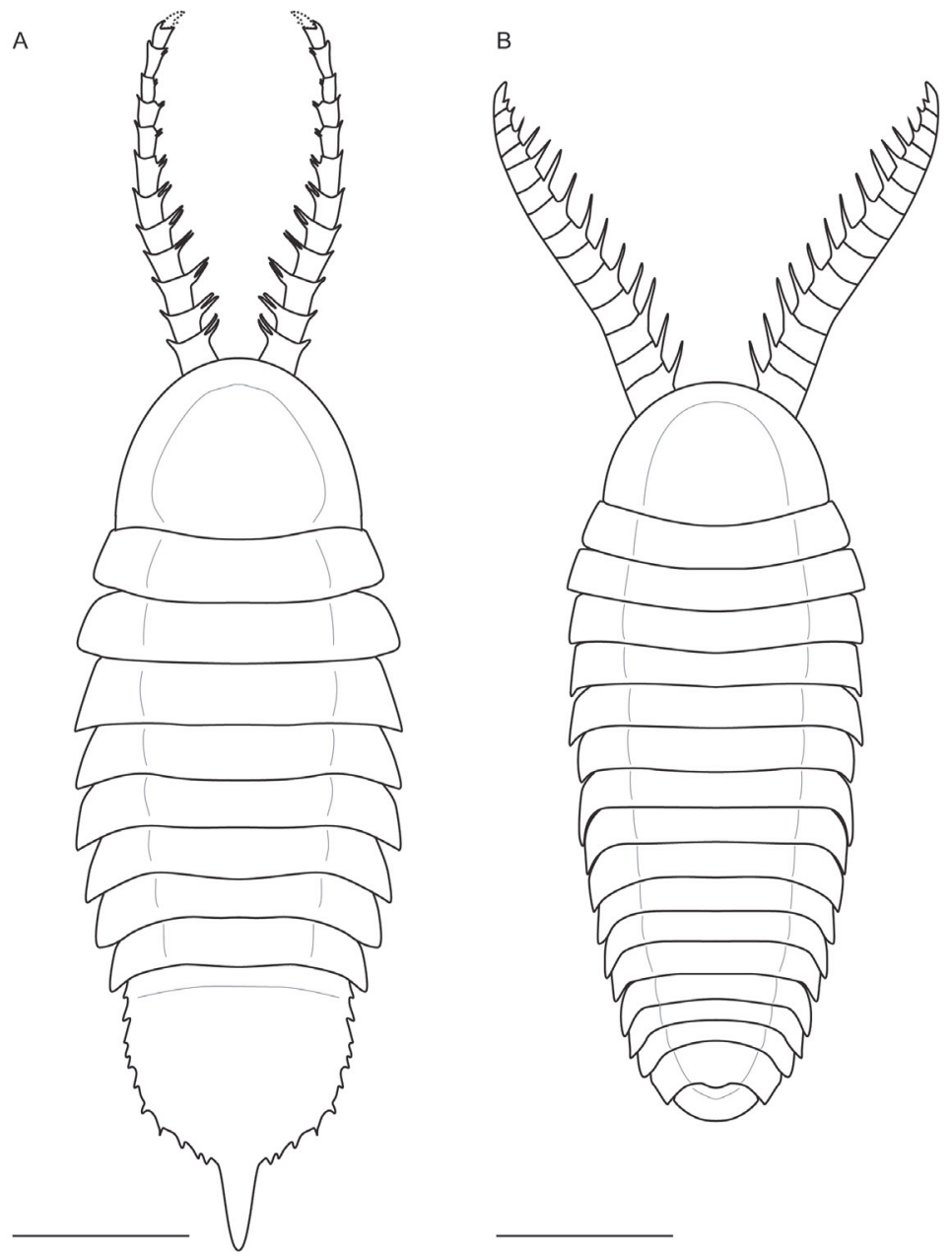

FIGURE 4. Reconstruction of A, Bushizheia yangi gen. et sp. nov. juxtaposed with B, Kiisortoqia soperi Stein 2010 (modified from Stein, 2010) in dorsal view. Both scale bars are $10 \mathrm{~mm}$.

ible axially. The tailspine is sub-triangular and incompletely articulated; it is as wide as long, circa $8 \%$ of the total length, and circa $30 \%$ of the total length of the pygidium.

Appendages (Figures 1A-B, 2A-D, 4A): The frontal head limbs reach a length of circa $33 \%$ of the total length of the body: 12 podomeres extend beyond the head shield, each with lateral endites that bear two inward facing setae, and terminal setae that are outward facing. Podomeres 2-7 are of equal length but decrease in width distally (Figures $1 \mathrm{~A}-\mathrm{B}$, 2A-B, 4A).

All visible post-frontal head limb appendages consist of either an endopod or an exopod. The one (incompletely) preserved endopod comprises four narrow podomeres (Figures 1A-B, 3A). The two preserved exopods are paddle-shaped flaps, fringed with setae (Figures 1A-B, 3B). Stein (2010), in his description of Kiisortoqia soperi, identified four cephalic appendiferous segments (a head incorporating the antennular plus three post-antennular limb-bearing segments), considered to be part of the ground pattern of Euarthropoda (Waloszek et al., 2007). The distal exopod of the anterior-most post-frontal head limb appendage of Bushizheia yangi gen. et sp. nov. appears beneath the head shield, and may, based on its position, be the fourth cephalic appendage. The limb immediately posterior of this, adjacent to the first trunk tergite, appears to be the first trunk appendage.

Remarks. Bushizheia yangi gen. et sp. nov. is dorsoventrally compressed and lies parallel to lamination; its well-articulated nature (i.e., tergites preserved attached, exopods preserved in situ). This state of preservation, especially the presence of articulated frontal head limbs, suggests limited post-mortem transportation: in, e.g., extant crustaceans, antennae can easily disarticulate (but see 
Allison, 1986). Compression wrinkles in the head shield that parallel its margin (Figures 1A-B, 2A-D), suggest localised, weak sclerotisation. It is, therefore, presumed that the head shield was a simple, convex shield, sclerotised but without substantial biomineralization.

As a result of the state of preservation, not all podomeres of the frontal appendages are accessible for a straightforward description. The exact number of podomeres cannot be established; some are obscured by sediment. Lateral endites can be confirmed for at least podomeres 2-7, 9, 11, 12 , and medial endites bearing two firm setae at their tips can be confirmed for at least $4,5,7,11$, and 12 (Figure 2A-B). Rotation of podomere 2 evinces widely spaced double rows of endites (Figures $1 \mathrm{~A}-\mathrm{B}, 2 \mathrm{~A}$ ).

Limbs with exopod setae are visible to the right of the two anterior-most thoracic tergites; the exopod of the posterior-most cephalic limb protrudes from beneath the head shield directly adjacent to the border of the head shield and first tergite, and is significantly rotated posteriorly, as is, albeit to a lesser extent the exopod of the first trunk limb. Only a single posteriorly situated endopod is, due to a degradation or complete absence of the overlying tergite, visible. No additional limbs were revealed by palaeontological techniques. The exact number of podomeres in the frontal appendages cannot be ascertained due to poor preservation of the distal-most ones. The proximal portions of the exopods are unavailable for description, so it cannot be established as to whether they were bipartite and divided into proximal and distal portions as in Leanchoilia illecebrosa (see Liu et al., 2007).

\section{DISCUSSION}

\section{Frontal Appendages}

Bushizheia yangi gen. et sp. nov. and Kiisortoqia soperi possess a long, grasping frontal appendage very similar to that of the radiodonts. However, neither of these two species closely resemble radiodonts. Could the presence of raptorial appendages in $B$. yangi gen. et sp. nov. and $K$. soperi be symplesiomorphic, shared by $B$. yangi gen. et sp. nov. and $K$. soperi - but also with radiodonts linked earlier in the clade, to which Stein (2010) alluded? Or are they an interesting case of convergence in organisms that are not closely related (not monophyletic), which independently evolved similar traits as a result of having to adapt to similar life habits?
It is beyond the scope of this article to attempt to solve the arthropod head problem. Indeed, the preservation of Bushizheia yangi gen. et sp. nov. does not allow assessment of the neurological connection of the raptorial appendage. Hence, we can only compare them to other appendages based on their morphology. Therefore, we explore the significance of the raptorial appendage of $B$. yangi gen. et sp. nov. and $K$. soperi in the context of some current interpretations of the homology of cephalic arthropodan appendages; more precisely, the interpretation of the nature of the 'great appendage' of radiodonts.

For Chen et al. (2004), Waloszek et al. (2005), Vannier et al. (2009), Haug et al. (2012a, 2012b), and Tanaka et al. (2013), the radiodonts, and other 'great appendage' arthropods belong to the lineage leading to chelicerates, and the 'great appendage' is homologous to the chelicera. Following this line of reasoning, the presence of the 'great appendage' in Bushizheia yangi gen. et sp. nov. and $K$. soperi would, in this case, most likely be homologous to the 'great appendage' of radiodonts. The presence of this 'great appendage' would tie $B$. yangi gen. et sp. nov., $K$. soperi, and 'great appendage' and 'short-great appendage' arthropods together. More precisely, within this group, $B$. yangi gen. et sp. nov., $K$. soperi and radiodonts would be one of the sister groups of chelicerates and 'short-great appendage' arthropods. The problem being to reconcile the apparently primitive scarcity of sclerites displayed by radiodonts with them being included in Euarthropoda, especially when considering that $B$. yangi gen. et sp. nov. and $K$. soperi are fully sclerotised. One solution to this problem would be to consider that radiodonts subsequently lost part of their tergites, perhaps due to their nektobenthic life habits. The sclerotisation of $B$. yangi gen. et sp. nov. and $K$. soperi in this scenario would then represent a primitive trait.

Another, currently more widely held view, is that radiodonts are not euarthropods, but belong to a series of sister groups to euarthropods (so called 'stem-group'), which documents the progressive transition from weakly sclerotised, segmented animals resembling lobopodians to fully sclerotised animals, the euarthropods (Waloszek et al., 2005). However, the results of two important phylogenies (Daley et al., 2009, Kühl et al., 2009) supporting this theory were criticised by Haug et al. (2012b) due to apparent discrepancies in the coding of some characters and taxa. The debate on the nature of radiodonts is not closed yet: the phylogenetic analyses of Legg and Vannier, (2013), Vin- 
ther et al. (2014), Yang et al. (2015, 2018), Moysiuk and Caron (2019) and Aria et al. (2020) support a 'stem-group' affinity for radiodonts. In this scheme, Bushizheia yangi gen. et sp. nov. and $K$. soperi clearly belong to euarthropods, as explained above, and in this scenario the appendage similarity is either a convergence with the 'great appendage' of radiodonts, or, the 'great appendage' was retained in early euarthropods, and lost, or modified beyond recognition in most lineages of euarthropods.

The convergence hypothesis agrees with the interpretation of Budd (2002), who considered the 'great appendage' to represent a pre-antennular appendage that was transformed into the labrum (see Scholtz and Edgecombe, 2006; Cong et al., 2014; Ortega-Hernández et al., 2017; Daley et al., 2018; Park et al., 2018) in the group including euarthropods (see also Eriksson et al., 2003) for which there are lines of evidence pro (e.g., Siewing, 1969; Lauterbach, 1973; Rempel, 1975), et contra (e.g., Walossek and Müller, 1998; Wolff, 2004; Mayer et al., 2014; Aria, 2020). If we subscribe to the hypothesis that the 'great appendage' was lost or reduced into the labrum, then the presence of 'great appendage'-like frontal head limbs require convergence. Such convergence can be easily explained if Bushizheia yangi gen. et sp. nov. and $K$. soperi used their frontal head limbs in a fashion like predatory radiodonts.

Contrary to this last hypothesis, the composition and morphology of the raptorial appendage of Bushizheia yangi gen. et sp. nov. bears a striking resemblance to the plesiomorphic state of the raptorial appendage within radiodonts (i.e., the predatory, microphagous species). Other, probably distantly related species also have a seemingly similar raptorial appendage, e.g., the bradoriid Kunmingella douvillei (Mansuy, 1912) (see Zhai et al., 2019). This could give credence to the hypothesis that the great appendage was not reduced in a group including euarthropods, but rather was lost or reduced in a group within euarthropods.

In the case of Bushizheia yangi gen. et sp. nov., since we do not have access to the ventral surface of the animal, we cannot describe the position of the raptorial appendage. This prevents observation of the connection of this appendage to the head, and its exact nature. We can only hope that better preserved specimens may help us understand this animal better, and perhaps lead to a better understanding of the arthropod head.

\section{Pygidium}

Despite its overall similarity to Kiisortoqia soperi and the morphological similarity of its appendages with those of the radiodonts, the posterior of the animal is quite different. Disparity between Bushizheia yangi gen. et sp. nov. and $K$. soperi in this regard may well indicate that these are not closely related organisms. On a similar line of thought, similitude between $B$. yangi gen. et sp. nov. and trilobitomorphs due to the presence of a pygidium could have been acquired by convergent evolution, an allusion to the conspicuous resemblance of the appendages of aglaspidid-like arthropods with those of the nektaspid Naraoia spinosa Zhang and Hou, 1985 (Zhang and Shu, 2005). Alternatively, a plesiomorphic pygidium was retained in various arthropod groups (see OrtegaHernández, 2013); such a scenario conflicts with Edgecombe and Ramsköld (1999), Cotton and Braddy (2004), and Paterson et al. $(2010,2012)$ in which the presence of the pygidium is synapomorphic for a clade composed by Xandarellida, Nektaspida, Conciliterga, and Trilobita.

Artiopoda Hou and Bergström, 1997 (e.g., Xandarellida, Nektaspida, Conciliterga and Trilobita) are arthropods with filiform antennulae (see Stein and Selden, 2011). Bushizheia yangi gen. et sp. nov is ipso facto outside Artiopoda, ergo the presence of the pygidium is not synapomorphic for a clade composed by the aforementioned groups. If the interpretation of a plesiomorphic pygidium is correct, this would indicate that this structure was retained in some arthropod groups (e.g., B. yangi gen. et sp. nov. and Trilobitomorpha) but lost in many others.

\section{PALAEOECOLOGY}

A variety of arthropods from the Chengjiang biota were most likely predators (Vannier and Chen, 2002; Chen et al., 2004). The frontal head limbs of Bushizheia yangi are sturdy, predatory appendages, reminiscent of the 'great appendage' of radiodonts. The presence of limbs posterior of these frontal head limbs that bear paddle-shaped exopods suitable for swimming could be indicative of a nektobenthic habit (Stein, 2010). No eyes could be found in the specimen. If the eyes in $B$. yangi gen. et $\mathrm{sp}$. nov. were situated under the anterior border of the head shield, as in e.g., Leanchoilia illecebrosa (Hou, 1987), it is possible that they, together with the other ventral features of that area, were not preserved. The alternative hypothesis is that $B$. yangi gen. et sp. nov. was blind. 
Although visual perception in animals plays an important role in prey detection, other senses are used by animals in pinpointing their prey; the absence of eyes does not preclude $B$. yangi gen. et sp. nov. from being a predator. In the case where visual perception is lacking, $B$. yangi gen. et $\mathrm{sp}$. nov. may have been an ambush predator, lying in wait, and catching unsuspecting prey with its anteroventral raptorial appendage.

\section{CONCLUSION}

Bushizheia yangi gen. et sp. nov. possesses a fully arthrodised body and limbs and consequently rests comfortably within the Euarthropoda (Aria, 2019). The present data neither confirms nor refutes any of the current interpretations of the homology of cephalic arthropodan appendages and although the phylogenetic position of $B$. yangi gen. et sp. nov. is difficult to resolve because few ventral structures are visible, the many euarthropod plesiomorphies possessed by the taxon may indicate a basal position of the species, and it demonstrates the importance of fossils in characterising ground patterns, as mentioned by, amongst other authors, Stein (2010).

The dorsoventrally flattened exoskeleton and paddle-shaped exopods that are suitable for swim- ming suggest a nektobenthic mode of life and Bushizheia yangi gen. et sp. nov. likely used its 'great appendage'-like frontal head limbs for predation.

\section{ACKNOWLEDGEMENTS}

We thank Z. Yang for discovering and preparing the specimen and donating it to the Yunnan Key Laboratory for Palaeobiology. We also thank H. Mai (Yunnan Key Laboratory for Palaeobiology) for performing computed tomography scans. We are indebted to D. Loydell and D. Martill (University of Portsmouth) for suggesting references and $\mathrm{J}$. Ortega-Hernández (Harvard University) and C. Haug (Ludwig-Maximilians-University) for discussions. We thank the editor and three anonymous reviewers for their helpful comments. The research of R.J. O'Flynn and D. Audo is supported by the China Postdoctoral Science Foundation, Yunnan Province Postdoctoral Science Foundation, NSFC grant (41861134032), Natural Science Foundation of Yunnan Province grants 2015HA021, 2018FA025, 2018IA073 and 2019DG050. This publication is undertaken under the auspices of the MEC International Joint Laboratory for Palaeobiology and Palaeoenvironment, Yunnan University, China.

\section{REFERENCES}

Allison, P.A. 1986. Soft-bodied animals in the fossil record: the role of decay in fragmentation during transport. Geology, 14:979-981. https://doi.org/10.1130/00917613(1986)14<979:SAITFR>2.0.CO;2

Aria, C. 2019. Reviewing the basis for a nomenclatural approach uniformization of the highest taxonomic levels in arthropods. Geological Magazine, 156:1463-1468. https://doi.org/ 10.1017/S0016756819000475

Aria, C., Zhao, F.-C., Zeng, H., Guo, J., and Zhu, M. 2020. Fossils from South China redefine the ancestral euarthropod body plan. BMC Evolutionary Biology, 20:4. https://doi.org/10.1186/ s12862-019-1560-7

Bengtson, S. 2000. Teasing fossils out of shales with cameras and computers. Palaeontologia Electronica, 3.1.4A:1-14. http://palaeo-electronica.org/2000_1/fossils/issue1_00.htm

Budd, G.E. 2002. A palaeontological solution of the arthropod head problem. Nature, 417:271275. https://doi.org/10.1038/417271a

Chen, J.-Y., Waloszek, D., and Maas, A. 2004. A new "great-appendage" arthropod from the Lower Cambrian of China and homology of chelicerate chelicerae and raptorial anteroventral appendages. Lethaia, 37:3-20. https://doi.org/10.1080/00241160410004764

Chen, X.-H., Ortega-Hernández, J., Wolfe, J.M., Zhai, D., Hou, X.-G., Chen, A.-L., Mai, H.-J., and Liu, Y. 2019. The appendicular morphology of Sinoburius lunaris and the evolution of the artiopodan clade Xandaellida (Euarthropoda, early Cambrian) from South China. BMC Evolutionary Biology, 19:165. https://doi.org/10.1186/s12862-019-1491-3

Cong, P.-Y., Ma, X.-Y., Hou, X.-G., Edgecombe, G.D., and Strausfeld, N.J. 2014. Brain structure resolves the segmental affinity of anomalocaridid appendages. Nature, 513:538-542. https:// doi.org/10.1038/nature13486 
Cotton, T.J. and Braddy, S.J. 2004. The phylogeny of arachnomorph arthropods and the origin of the Chelicerata. Earth and Environmental Science Transactions of the Royal Society of Edinburgh, 94:169-193. https://doi.org/10.1017/S0263593300000596

Daley, A.C., Antcliffe, J.B., Drage, H.B., and Pates, S. 2018. Early fossil record of Euarthropoda and the Cambrian Explosion. Proceedings of the National Academy of Sciences of the United States of America, 115:5323-5331. https://doi.org/10.1073/pnas.1719962115

Daley, A.C., Budd, G.E., Caron, J., Edgecombe, G.D., and Collins, D. 2009. The Burgess Shale anomalocaridid Hurdia and its significance for early euarthropod evolution. Science, 323:1597-1600. https://doi.org/10.1126/science.1169514

Daley, A.C. and Edgecombe, G.D. 2014. Morphology of Anomalocaris canadensis from the Burgess Shale. Journal of Paleontology, 88:68-91. https://doi.org/10.1666/13-067

Du, K.-S., Ortega-Hernández, J., Yang, J., and Zhang, X.-G. 2018. A soft-bodied euarthropod from the early Cambrian Xiaoshiba Lagerstätte of China supports a new clade of basal artiopodans with dorsal ecdysial sutures. Cladistics, 35:269-281. https://doi.org/10.1111/ cla.12344

Edgecombe, G.D. and Ramsköld, L. 1999. Relationships of Cambrian Arachnata and the systematic position of Trilobita. Journal of Paleontology, 73:263-287. https://doi.org/10.1017/ S0022336000027761

Eriksson, B.J., Tait, N.N., and Budd, G.E. 2003. Head development in the onychophoran Euperipatoides kanangrensis with particular reference to the central nervous system. Journal of Morphology, 255:1-23. https://doi.org/10.1002/jmor.10034

Fu, D.-J., Zhang, X.-L., and Shu D.-G. 2011. Soft anatomy of the Early Cambrian arthropod Isoxys curvirostratus from the Chengjiang biota of South China with a discussion on the origination of great appendages. Acta Paleontologica Polonica, 56:843-852. https://doi.org/ 10.4202/app.2010.0090

Haug, J.T., Briggs, D.E.G., and Haug, C. 2012a. Morphology and function in the Cambrian Burgess Shale megacheiran arthropod Leanchoilia superlata and the application of a descriptive matrix. BMC Evolutionary Biology, 12:162. https://doi.org/10.1186/1471-2148-12162

Haug, J.T., Waloszek, D., Maas, A., Liu, Y., and Haug, C. 2012b. Functional morphology, ontogeny and evolution of mantis shrimp-like predators in the Cambrian. Palaeontology, 55:369-399. https://doi.org/10.1111/j.1475-4983.2011.01124.x

Hou, X.-G. 1987. Three new large arthropods from the Lower Cambrian, Chengjiang, eastern Yunnan: Acta Palaeontologica Sinica, 26:272-285. (In Chinese)

Hou, X.-G. and Bergström, J. 1997. Arthropods of the Lower Cambrian Chengjiang Fauna, southwest China. Fossils and Strata, 45:1-116.

Hou, X.-G., Siveter, D.J., Siveter, D.J., Aldridge, R.J., Cong, P.-Y., Gabbott, S.E., Ma, X.-Y., Purnell, M.A., and Williams, M. 2017. The Cambrian Fossils of Chengjiang, China: The Flowering of Early Animal Life, Second Edition. Wiley-Blackwell, Chichester, West Sussex.

Kühl, G., Briggs, D.E.G., and Rust, J. 2009. A great-appendage arthropod with a radial mouth from the Lower Devonian Hunsruck Slate, Germany. Science, 323:771-773. https://doi.org/10.1126/science.1166586

Lankester R.E. 1904. The structure and classification of the Arthropoda. Quarterly Journal of Microscopical Science, 47:523-582.

Lauterbach, K.E. 1973. Schlüsselereignisse in der Evolution der Stammgruppe der Euarthropoda. Zoologische Beiträge, 19:251-299.

Legg, D. and Vannier, J. 2013. The affinities of the cosmopolitan arthropod Isoxys and its implications for the origin of arthropods. Lethaia, 46:540-550. https://doi.org/10.1111/ let.12032

Liu, Y., Hou, X.-G., and Bergström, J. 2007. Chengjiang Arthropod Leanchoilia illecebrosa (Hou, 1987) reconsidered. Journal of the Geological Society of Sweden, 129:263-272. https://doi.org/10.1080/11035890701293263

Mansuy, H. 1912. Part 2, Paléontogie, p. 1-31. In Deprat, J. and Mansuy, H. (eds.), Etude Géologique du Yunnan Oriental. Mémoire du Service Géologique de l'Indochine.

Mayer, G., Martin, C., Olivereira, I.S., Franke, F.A., and Gross, V. 2014. Latest anomalocaridid affinities challenged. Nature, 516:E1-E2. https://doi.org/10.1038/nature13860

Moysuik, J. and Caron, J.-B. 2019. A new hurdiid radiodont from the Burgess Shale evinces the exploitation of Cambrian infaunal food sources. Proceedings of the Royal Society B, 286:20191079. https://doi.org/10.1098/rspb.2019.1079 
Ortega-Hernández, J., Legg, D.A., and Braddy, S.J. 2013. The phylogeny of aglaspidid arthropods and the internal relationships within Artiopoda. Cladistics, 29:15-45. https://doi.org/10.1111/j.1096-0031.2012.00413.x

Ortega-Hernández, J. 2014. Making sense of 'lower' and 'upper' stem-group Euarthropoda, with comments on the strict use of the name Arthropoda von Siebold, 1848. Biological Reviews, 91:255-273. https://doi.org/10.1111/brv.12168

Ortega-Hernández, J., Janssen, R., and Budd, G.E. 2017. Origin and evolution of the panarthropod head - A palaeobiological and developmental perspective. Arthropod Structure and Development, 46:354-379. https://doi.org/10.1016/j.asd.2016.10.011

Park, T.-Y.S., Kinm, J.-H., Woo, J., Park, C., Lee, W.Y., Smith, P., Harper, D.A.T., Young, F., Nielsen, A.T., and Vinther, J. 2018. Brain and eyes of Kerygmachela reveal protocerebral ancestry of the panarthropod head. Nature Communications, 9:1019. https://doi.org/10.1038/ s41467-018-03464-w

Paterson, J.R., Edgecombe, G.D., García-Bellido, D.C., Jago, J.B., and Gehling, J.G. 2010. Nektaspid arthropods from the lower Cambrian Emu Bay Shale Lagerstätte, South Australia, with a reassessment of lamellipedian relationships. Palaeontology, 53:377-402. https:// doi.org/10.1111/j.1475-4983.2010.00932.x

Paterson, J. R., García-Bellido, D.C., and Edgecombe, G.D. 2012. New artiopodan arthropods from the early Cambrian Emu Bay Shale Konservat-Lagerstätte, South Australia. Journal of Paleontology, 86:340-357. https://doi.org/10.1666/11-077.1

Rempel, J.G. 1975. The evolution of the insect head: the endless dispute. Quaestiones Entomologicae, 11:7-25.

Schneider, C.A., Rasband, W.S., and Eliceriri, K.W. 2012. NIH Image to ImageJ: 25 years of image analysis. Nature Methods, 9:671-675. https://doi.org/10.1038/nmeth.2089

Scholtz, G. and Edgecombe, G.D. 2006. The evolution of arthropod heads: reconciling morphological, developmental and palaeontological evidence. Developmental Genes and Evolution, 216:395-415. https://doi.org/10.1007/s00427-006-0085-4

Siewing, R. 1969. Lehrbuch der vergleichenden Entwicklungsgeschichte der Tiere. Paul Parey, Hamburg.

Stein, M. 2010. A new arthropod from the Early Cambrian of North Greenland, with a 'great appendage'-like antennula. Zoological Journal of the Linnean Society, 158:477-500. https:// doi.org/10.1111/j.1096-3642.2009.00562.x

Stein, M. and Selden, P.A. 2011. A restudy of the Burgess Shale (Cambrian) arthropod Emeraldella brocki and reassessment of its affinities. Journal of Systematic Palaeontology, 10:361-383. https://doi.org/10.1080/14772019.2011.566634

Tanaka, G., Hou, X.-G., Ma, X.-Y., Edgecombe, G.D., and Strausfeld. N.J. 2013. Chelicerate neural ground pattern in a Cambrian great appendage arthropod. Nature, 502:364-367. https://doi.org/10.1038/nature12520

Vannier, J. and Chen, J.-Y. 2002. Digestive systems and feeding mode in Cambrian naraoiid arthropods. Lethaia, 35:107-120. https://doi.org/10.1111/j.1502-3931.2002.tb00072.x

Vannier, J., García-Bellido, D.C., Hu, S.-X., and Chen A-L.. 2009. Arthropod visual predators in the early pelagic ecosystem: evidence from the Burgess Shale and Chengjiang biotas. Proceedings of the Royal Society B, 276:2567-2574. https://doi.org/10.1098/rspb.2009.0361

Vinther, J., Stein, M., Longrich, N.R., and Harper, D.A.T. 2014. A suspension-feeding anomalocarid from the Early Cambrian. Nature, 507:496-499. https://doi.org/10.1038/ nature13010

Walossek D. and Müller K.J. 1998. Cambrian 'Orsten'-type arthropods and the phylogeny of Crustacea, p. 139-153. In Fortey, R.A. and Thomas, R.H. (eds.), Arthropod Relationships. The Systematics Association Special Volume Series, vol 55. Springer, Dordrecht. https://doi.org/10.1007/978-94-011-4904-4_12

Waloszek, D., Chen J.-Y., Maas A., and Wang X.-Q. 2005. Early Cambrian arthropods: new insights into arthropod head and structural evolution. Arthropod Structure and Development, 34:189-205. https://doi.org/10.1016/j.asd.2005.01.005

Waloszek, D., Maas, A., Chen, J.-Y., and Stein, M. 2007. Evolution of cephalic feeding structures and the phylogeny of Arthropoda. Palaeogeography, Palaeoclimatology, Palaeoecology, 254:273-287. https://doi.org/10.1016/j.palaeo.2007.03.027

Wolff, C. 2004. Die Beinentwicklung des amphipodan Krebses Orchestia cavimana (Peracarida, Malacostraca - eine zellgenealogishe Studie. Unpublished PhD Thesis, HumboldtUniversität zu Berlin. 
Yang, J., Ortega-Hernández, J., Gerber, S., Butterfield, N.J., Hou, J.-B., Tian, L., and Zhang, X.G. 2015. A superarmored lobopodian from the Cambrian of China and early disparity in the evolution of Onychophora. Proceedings of the National Academy of Sciences, 112:86788683. https://doi.org/10.1073/pnas.1505596112

Yang, J., Ortega-Hernández, J., Legg, D.A., Tian, L., Hou, J.-B., and Zhang, X.-G. 2018. Early Cambrian fuxianhuiids from China reveal origin of the gnathobasic protopodite in euarthropods. Nature Communications, 9:470. https://doi.org/10.1038/s41467-017-02754-z

Zhai, D.-Y., Williams, M., Siveter, D.J., Harvey, T.H.P., Sansom, R.S., Gabbott, S.E., Siveter, D., Ma, X.-Y., Zhou, R.-Q., Liu, Y., and Hou, X.-G. 2019. Variation in appendages in early Cambrian bradoriids reveals a wide range of body plans in stem-euarthropods. Communications Biology, 2:329. https://doi.org/10.1038/s42003-019-0573-5

Zhang, W.-T. and Hou, X.-G. 1985. Preliminary notes on the occurrence of the unusual trilobite Naraoia in Asia. Acta Palaeontologica Sinica, 24:591-595. (In Chinese with English summary)

Zhang, X.-L. and Shu, D.-G. 2005. A new arthropod from the Chengjiang Lagerstätte, Early Cambrian, southern China. Alcheringa, 29:185-194. https://doi.org/10.1080/ 03115510508619300

Zhu, M.-Y., Zhu, J.-M., and Li, J.-X. 2001. Sedimentary environments of the Early Cambrian Chengjiang biota: sedimentology of the Yu'anshan Formation in Chengjiang County, Eastern Yunnan. Acta Palaeontologica Sinica, 40:80-105. 